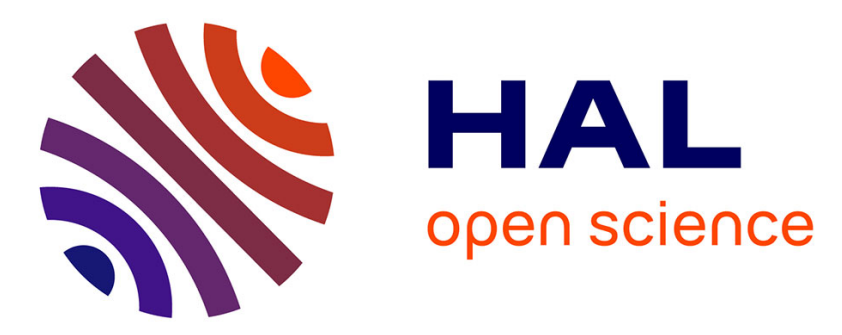

\title{
Relevance of orchard design issuing from growers' planting choices to study fruit tree cropping systems
}

Thomas Nesme, Françoise Lescourret, Stephane Bellon, Daniel Plénet, Robert Habib

\section{- To cite this version:}

Thomas Nesme, Françoise Lescourret, Stephane Bellon, Daniel Plénet, Robert Habib. Relevance of orchard design issuing from growers' planting choices to study fruit tree cropping systems. Agronomie, 2003, 23 (7), pp.651-660. 10.1051/agro:2003043 . hal-00886221

\section{HAL Id: hal-00886221 \\ https://hal.science/hal-00886221}

Submitted on 1 Jan 2003

HAL is a multi-disciplinary open access archive for the deposit and dissemination of scientific research documents, whether they are published or not. The documents may come from teaching and research institutions in France or abroad, or from public or private research centers.
L'archive ouverte pluridisciplinaire HAL, est destinée au dépôt et à la diffusion de documents scientifiques de niveau recherche, publiés ou non, émanant des établissements d'enseignement et de recherche français ou étrangers, des laboratoires publics ou privés. 


\title{
Relevance of orchard design issuing from growers' planting choices to study fruit tree cropping systems
}

\author{
Thomas NESME ${ }^{a *}$, Françoise LESCOURRET ${ }^{\mathrm{a}}$, Stéphane BELLON ${ }^{\mathrm{b}}$, Daniel PlÉNET ${ }^{\mathrm{a}}$, Robert HABIB ${ }^{\mathrm{a}}$ \\ a Institut National de la Recherche Agronomique, Unité Plante et Système de culture Horticoles, Domaine Saint-Paul, Site Agroparc, \\ 84914 Avignon Cedex 9, France \\ b Institut National de la Recherche Agronomique, Unité d’Écodéveloppement, Domaine Saint-Paul, Site Agroparc, 84914 Avignon Cedex 9, France
}

(Received 26 August 2002; accepted 16 May 2003)

\begin{abstract}
Fruit tree cropping system comprehension, useful for changing orchardists' practices, needs to take into account long-term determinants. Therefore, we aimed at understanding to what extent orchard design issuing from planting choices influenced present cultural practices and crop performances. Data from 91 plots located in Southeastern France allowed the identification of 4 groups according to the date and planting choices (variety, rootstock, density, planting distances and tree shape). Orchard designs discriminated the old low density Golden orchards from the recent moderately dense Gala orchards, passing by intensive Granny orchards of the 70s. They influenced present cultural practices: old orchards receive significantly more water and dormant pruning than younger orchards. Present agronomical performances were also discriminated by this typology: the most recent plots had lower total fresh yield and fruit defaults than old orchards. Thus, orchard design, which emerges from on-field observation, could be used to study fruit tree cropping systems and be considered in stratified sampling for plot comparison in agronomical regional diagnosis.
\end{abstract}

cropping system / apple tree / planting choices / orchard design / cultural practices

Résumé - Importance des conceptions de vergers issus des choix de plantation des producteurs pour l'étude des systèmes de culture fruitiers arboricoles. La compréhension des systèmes de culture fruitiers arboricoles, utile pour le changement des pratiques des arboriculteurs, repose sur la prise en compte des déterminants à long terme. Ainsi, nous avons cherché à savoir dans quelle mesure les conceptions de vergers issues des choix de plantation influencent les pratiques culturales et les performances agronomiques de la culture. Un jeu de données issu de 91 parcelles situées dans le Sud-Est de la France a permis d'identifier 4 groupes selon la date et les choix de plantation (variété, porte-greffe, densité, distances de plantation et forme de l'arbre). La typologie sépare bien les vieux vergers peu denses de Golden des vergers récents et modérément denses de Gala, en passant par les vergers intensifs de Granny des années 1970. Les conceptions de verger influencent les pratiques culturales actuelles : les vieux vergers reçoivent significativement plus d'eau et de taille d'hiver que les jeunes vergers. Les performances agronomiques sont aussi influencées par les conceptions de verger : les parcelles les plus récentes ont des rendements totaux frais plus faibles et des fruits moins entachés de défauts que les vieux vergers. Ainsi, la conception de verger, qui émerge de l'observation de la réalité des parcelles agricoles peut être utilisée pour ordonner la diversité des systèmes de culture et prise en compte dans le plan d'échantillonnage lors de la comparaison de parcelles destinée au diagnostic agronomique régional.

système de culture / pommier / choix de plantation / conception de verger / pratique culturale

\section{INTRODUCTION}

The cultivated field is a complex object which involves three main interacting compartments: soil conditions, plants and cultivation techniques. Moreover, these three compartments are managed by a farmer, who must face agronomical, economical, environmental, temporal and financial constraints and objectives. The cultivated field is located in two contexts: spatial (the landscape) and temporal (the past and the future of the field). To take into account this complexity, the concept of the cropping system has been set up [35], that can be summarised as a group of plots treated in a homogeneous way and characterised by the nature of the crops, their succession order and the crop management sequence they undergo.

Time is an essential component of cropping systems. It structures the chaining of both cultural operations and crop management sequences, with a short-term effect between a preceding and a following crop $[4,35]$, and a long-term cumulative effect 
$[11,18,20]$. Few studies have been conducted on the long-term impact of initial plot characteristics on present cropping systems (with the exception of Debaeke [10] who studied the impact of weed seed bank on weed management), probably because most of the research on cropping systems has been realised on annual crops that appear to depend on short-term plot determinants. But in perennial crops, a diachronic point of view is particularly interesting for studies dealing with the behaviour of cropping systems over time.

Fruit tree growing is an example of a perennial crop. The choices made at planting and during the first juvenile years of the orchard (variety, rootstock, shape of the trees and density) may be important for present orchard management, as they give a potential to the plot production and may influence present cultural practices.

The apple crop is an interesting example of fruit growing as it has a low varieties renewal rate, making possible a study on the long-term effect of planting choices. Moreover, it is concerned by the development of Integrated Fruit Production (IFP) principles [33] leading to fruit traceability from the plot to the commercial lot, and to recordings of cultural practices by farmers [15]. Most French Southeastern apple production is concentrated in Producers' Organisations (PO) which make the access to farmers' records easier, provide numerous fruit quality measurements and centralise orchard descriptions. Therefore, a great amount of data about cultural practices and fruit production is available in PO implementing IFP principles.

In this work, we used apple crops as a case study to examine to what extent planting choices influence present cropping systems. This paper presents the original data collection resulting from a network of apple farmer-plots, gathered in a PO, and analyses the relationships between planting choices and both cultural practices and agronomical performances.

\section{STUDY AREA, MATERIALS AND METHODS}

\subsection{Study area and data collection}

The data were collected from a network of apple tree plots owned by 31 growers grouped in a producer organisation. The region is located in Southeastern France, between Nîmes and Montpellier $\left(43.66^{\circ} \mathrm{N}, 4.11^{\circ} \mathrm{E}\right)$. The climate is Mediterranean and the distribution of soils is quite diverse. The apple trees are mainly located on four types of soils: resulting from alluvial deposits (fluviosol, according to the classification of Baize and Girard [1]), characterised or not by hydromorphy; brown calcareous soils (brunisol); red Mediterranean soils (fersialsol), and marsh hydromorphic soils (reducti-redoxisol). In 1999, the whole apple production of the PO represented 18000 tons. All the plots cover 387 ha, included in a circle of $20 \mathrm{~km}$ diameter. For this study, only the year 1999, 91 plots and 3 varieties (Golden, Granny and Gala, described in Tab. I) were considered, representing 213 ha (i.e. more than $90 \%$ of adult orchards, for these 3 varieties), 31 producers and 7071 tons. In comparison, the whole Southeastern fruit basin production for these 3 varieties in 1999 was 377664 tons [42], which gives a sampling rate of $1.87 \%$. The 1999 climate was fairly normal: no spring frost, no hot summer temperatures, a water deficit a little lower than the observed mean between 1972 and 2000 (486 mm vs. $524 \mathrm{~mm}$ ), and normal rainfall (673 $\mathrm{mm}$ vs. $656 \mathrm{~mm})$. For this year, 21 plots were considered in alternate bearing (the 1999 yield greater than $150 \%$ of the 1998 yield or smaller than $50 \%$ of the 1998 yield).

The data set concerns the perennial traits of orchards, the main cultural practices and the fruit harvests and quality as evaluated in the PO. As the elementary piece of the study is the cultural plot, all the data are related to this scale. The data originates from four sources: the "orchard inventory", fruit production measured by the PO, farmers' records and interviews. The "orchard inventory" describes the perennial traits in each plot for each farmer: year of planting, variety, clone, rootstock, planting distances, density and surface. Agronomical performances (yield and fruit quality) are measured by the PO as follows. Each fruit batch from the field is controlled by sampling when entering the co-operative for quality criteria. The production of a plot is delivered to the co-operative by means of 5.3 batches on average (varying from 1 to 63 batches per plot, depending on the plot size and production). Visual defaults are estimated manually on a sample of 100 fruits per batch. Sugar content and firmness rating are estimated with a refractometer and a penetrometer, respectively, on samples of 10 fruits per batch. Quality assessment is the same for all varieties. Two sources of information were used to describe the cultural practices: (i) the records kept by farmers, which are mandatory due to the specifications of IFP to which producers adhere, and (ii) a series of "close-ended" interviews of farmers which took place in May-June 2000. The records mainly concern irrigation, fertilisation and fruit thinning. They describe, for each cultural plot and each operation, the date, the conditions and the amounts applied. The interviews aimed at describing the orchard management (tree shape, thinning, pruning type, intensity and date), the present state of the crop (such as vigour or height) and the irrigation equipment. All the data were gathered in a database consistent with the information structure available in the PO [17].

We did not take into account the crop protection practices, under the assumption that they were at the agronomical maximum and therefore independent from other cultural practices and from planting choices (even from the variety, the three studied varieties being equally sensitive to apple scab and codling moth, the two main bioagressors, see Tab. I). This assumption is based on: (i) the importance of protection for the grower's benefit (fruits must present no default to be sold); (ii) the importance of crop protection in IFP specifications (in terms of authorised or forbidden chemicals, of sprayer control, of conditions of application, etc.), and (iii) the supervision of these practices offered by different advisers (co-operative, technical centre and plant protection administration). We tested this hypothesis through an analysis of visual fruit defaults, likely to reveal any lack of crop protection.

\subsection{Data analysis}

The variables related to orchard planting choices (variety, clone, date of planting, rootstock, tree shape, within- and between-row distances and density) were submitted to a correspondence analysis (CA) [13]. The interpretation of the CA 
Table I. Description of the studied varieties, from Trillot [39]. The sugar content is hereby estimated through the refractometric index. The type of fructification refers to the classification proposed by Lespinasse [26]: Type III concerns varieties for which fructification occurs on young shoots (from 1 to 3 years old) made of spurs and crown shoots. Type IV refers to varieties for which fructification occurs on very young shoots ( 1 or 3 years old), made of spurs on terminal position. These varieties tend to develop the ramification on the upper third of the branch and to localise the production on the periphery of the tree.

\begin{tabular}{|c|c|c|c|}
\hline Variety & Golden & Granny & Gala \\
\hline Year of selection & 1880 & 1850 & 1939 \\
\hline Colour & Yellow & Green & Bi-colour \\
\hline Sugar content $\left({ }^{\circ}\right.$ Brix $)$ & 13 to 15 & 11 to 12 & 12 to 14 \\
\hline Firmness & Mean & High & High \\
\hline Vigour & Average to high & $\begin{array}{l}\text { High without affecting tree } \\
\text { balance }\end{array}$ & Average to high, stronger than Golden \\
\hline Type of fructification & Type III & Type IV & Type III \\
\hline Fruiting & $\begin{array}{l}\text { Quick and regular Can be subject to } \\
\text { alternate bearing if bad equilibrium } \\
\text { between vigour and fruiting }\end{array}$ & Quick and important & Very quick \\
\hline Productivity & High to very high & High & Very high \\
\hline Pruning objectives & $\begin{array}{l}\text { Favouring the emission of crown shoot to } \\
\text { favour fruit quality and homogeneity and } \\
\text { to diminish alternate bearing risks }\end{array}$ & $\begin{array}{c}\text { Few pruning requirements: can } \\
\text { tolerate several years without } \\
\text { pruning }\end{array}$ & $\begin{array}{l}\text { Favouring crown shoot emission and } \\
\text { lighting of the tree. A summer pruning is } \\
\text { often recommended }\end{array}$ \\
\hline Harvest period & 1st September decade & 1 st or 2 nd October decade & 2nd to 3 rd August decade, in 3 or 4 runs \\
\hline Fruit sensitivity & Very sensitive to knocks & $\begin{array}{l}\text { Getting yellow or pink if picked } \\
\text { up too late. Low sensitivity to } \\
\text { knocks }\end{array}$ & $\begin{array}{l}\text { Needs manual thinning to be well } \\
\text { coloured. Sensitive to knocks in the case of } \\
\text { over-irrigation or maturity. }\end{array}$ \\
\hline Apple scab sensitivity & Average to high & Average & Average \\
\hline $\begin{array}{l}\text { Clones (name and year of } \\
\text { inscription in France) }\end{array}$ & Smothee (1982) & - & $\begin{array}{c}\text { Royal (1981) } \\
\text { Mondial (1985) } \\
\text { Galaxy (1993, highly coloured) } \\
\text { Imperial }\end{array}$ \\
\hline
\end{tabular}

was mainly based on the contributions of the modalities of the variables to factors. Then, plots were described by their coordinates on the first two factors of the CA and classified using the k-mean method, based on the calculation of the centroid of each cluster [29]. Four groups were created and projected on the factorial plane. They were represented by variance ellipses indicating $95 \%$ of the plots of the considered cluster.

Classes of visual fruit defaults were built by clustering plots without any previous CA: each of the 100 sampled fruits per batch was described by its main defaults (among a list of 21 possible defaults) or classified as non-defective. The occurrence frequency of each default was averaged per plot and constituted the default profile to which the clustering method was applied. The links between clusters of plots, representing classes of planting choices, and the cultural practices or agronomical performances were studied with different statistical methods. For quantitative variables, the homogeneity of variance between classes of planting choices was checked with a non-parametrical test of multiple comparison [37]. If variances were homogeneous, a classical analysis of variance was performed and possibly followed by multiple comparison Tukey tests. When heteroscedasticity was encountered, non-parametric analysis of variance (Kruskal-Wallis rank sum test) and multiple comparison tests (Noether test) were performed [34].
For qualitative variables, cross-tabulation analysis was used. The data analysis was conducted with S+2000 software [29].

\section{RESULTS AND INTERPRETATION}

\subsection{A plot typology reflecting the history of planting choices and orchard design}

The projection of the modalities of the variables representing the planting choices on the plane formed by the first two factors is shown in Figure 1. The third factor of the CA did not offer easy interpretation. The first factor $(16 \%$ of the total variance) opposes Golden orchards, planted between 1957 and 1969, with the highest within-row distances, to the right, with orchards planted between 1979 and 1989, with intermediate density (1500 to $\left.1800 \mathrm{tree} \cdot \mathrm{ha}^{-1}\right)$, to the left. The second factor (12\% of the total variance) opposes orchards with the highest density, the smallest within-row distances, planted between 1969 and 1979 with M106 rootstock, at the bottom, with the plots most recently planted with within-row distances between 1.5 and $2 \mathrm{~m}$, at the top. Contribution analysis shows that the first axis is mainly determined by the modalities located at the right of the figure: "planting 1957-69" (16\% of total contributions), "maximal within-row distance" (16\%) 


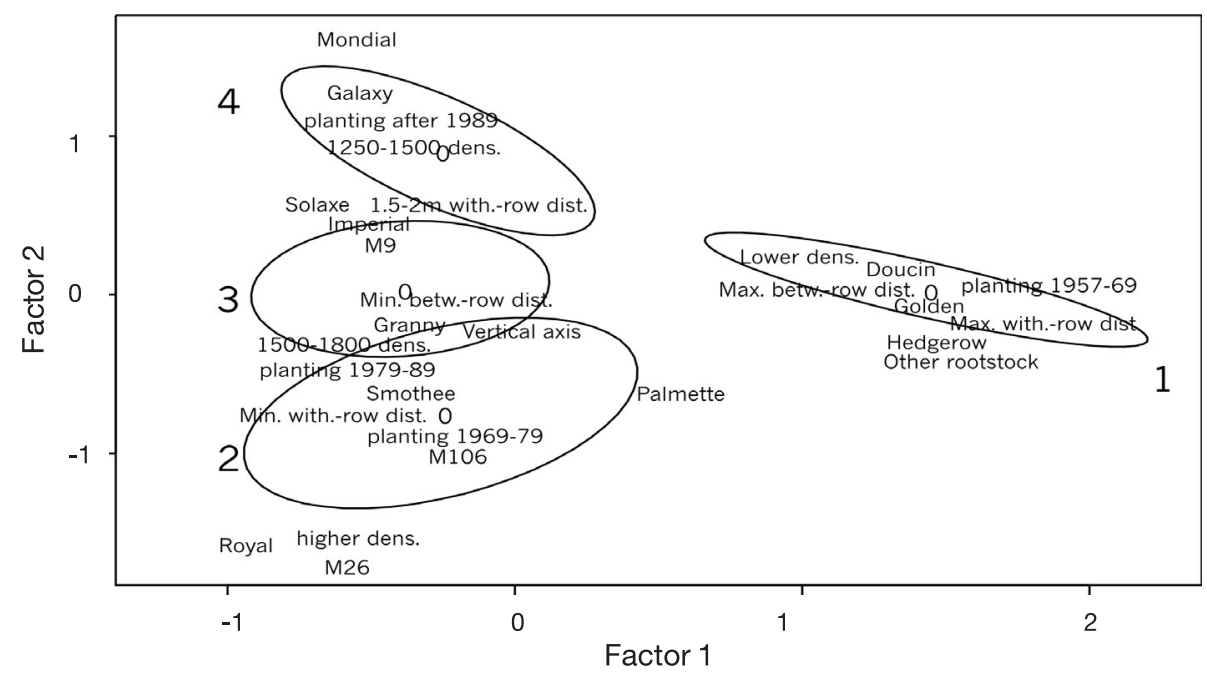

Figure 1. Box plots representing the annual amounts of water according to the orchard design. The horizontal white layer, the extremities of the rectangular, the square bracket and the extreme strokes represent the mean, the upper and lower quartile, the upper and lower extreme (excluding outliers) and the outliers of the variable, respectively. Anything farther than 1.5 times the inter-quartile range is considered outlier. The disposition of orchard design indices on the $\mathrm{x}$-axis corresponds to a temporal axis. Orchard number 1 is the oldest whereas number 4 is the youngest. Different letters situated in front of the mean indicate significant differences at the $P=0.05$ level with a Tukey test. and "Golden" (12\%). The second axis is mainly determined by the modalities "planting after 1989" (14\%), "highest density" (12\%) and "M26" (8\%). Four clusters were created on the basis of the plot coordinates; they clearly reflect the time of planting. On the right, the 1st group gathers the oldest plots, planted with Golden on vigorous rootstock (Doucin), with high planting distances (and so, a low density) and the hedgerow system tree shape. The second group is located bottom left and gathers old orchards (planted between 1969 and 1979) with less vigorous rootstock (M106 and M26), and the highest density. It is constituted of cv. Granny and a more recent Golden clone (Smothee), which can be conducted as a vertical axis. The third group associates plots planted between 1979 and 1989 mainly with Granny cv. (53\%), with intermediate densities (from 1250 to 1800 trees $\cdot \mathrm{ha}^{-1}$ ) and low withinand between-row distances. The last group, situated at the left top, represents Gala and Galaxy orchards (with, eventually, Gala clones such as Mondial or Imperial), recently planted (after 1989) on low vigorous rootstocks such as M9 and pruned according to the Solaxe principles. The main characteristics of the clusters are summarised in Table II.
According to the planting date, which is the main trait of this orchard classification, different patterns of orchards can be distinguished: from the old and low density Golden orchards (group 1), to the recent and moderate density Gala orchards (group 4), passing by the high density Granny orchards (group 2). We propose to summarise these characteristics, which correspond to perennial traits, by the term "orchard design".

\subsection{How do orchard designs influence cultural practices?}

\subsubsection{Input management}

According to the analysis of variance, the annual amounts of water supplied to the orchard vary between orchard designs (Fig. 2). Old orchards (group 1) receive more water than groups 3 and 4 . This is consistent with the fact that submersion irrigation, known to carry and waste a lot of water, is mainly represented in group 1 (nearly $25 \%$ of the plots are irrigated in such a way against less than $10 \%$ for the other groups). It is

Table II. Main characteristics of the 4 clusters of plots built on perennial descriptors. For each cluster and each variable, only the most important modalities are presented. The numbers between brackets are frequencies (\% of plots in the group).

\begin{tabular}{|c|c|c|c|c|}
\hline & Group 1 & Group 2 & Group 3 & Group 4 \\
\hline Number of plots & 17 & 22 & 36 & 16 \\
\hline Date of planting & $1957-1969(88 \%)$ & $1969-1979(63 \%)$ & $1979-1989(56 \%)$ & After $1989(88 \%)$ \\
\hline Variety and clones & Golden $(82 \%)$ & Granny (36\%) Smothee (40\%) & Granny $(53 \%)$ & Gala (31\%) Galaxy (31\%) \\
\hline Tree shape & Vertical (59) Hedgerow (29) & Vertical $(72 \%)$ & Vertical $(64 \%)$ Solaxe $(31 \%)$ & Vertical $(50 \%)$ Solaxe $(50 \%)$ \\
\hline Rootstock & Other Rootstock (59\%) & M106 (32\%) & M9 (89\%) & M9 (100\%) \\
\hline $\begin{array}{l}\text { Within-row } \\
\text { distances (m) }\end{array}$ & $>2(88 \%)$ & $<1.5(69 \%)$ & Between 1.5 and $2(53 \%)$ & Between 1.5 and $2(100 \%)$ \\
\hline $\begin{array}{l}\text { Between-row } \\
\text { distances (m) }\end{array}$ & - & $<4(95 \%)$ & $<4(89 \%)$ & $<4(100 \%)$ \\
\hline Density (trees $\cdot \mathrm{ha}^{-1}$ ) & $<1250(100 \%)$ & $>1800(64 \%)$ & Between 1500 and $1800(61 \%)$ & Between 1250 and $1500(56 \%)$ \\
\hline
\end{tabular}




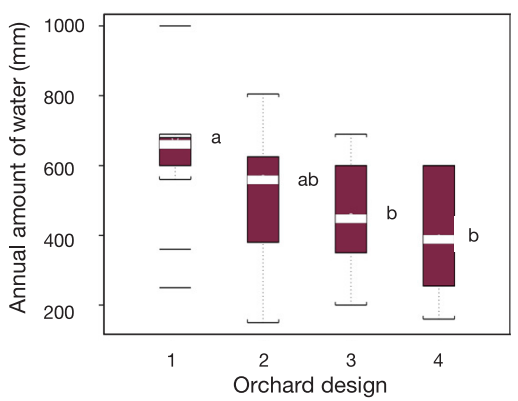

Figure 2. Orchard perennial traits (projection on the plane formed by factors 1 and 2 of the CA). Plot clusters based on plot coordinates on the first two factors are represented by variance ellipses (confidence level: $95 \%$ ). The letters located next to the ellipses refer to the cluster numbers used in the text. Min. betw.-row dist. = minimal betweenrow distance; Max. betw.-row. dist. = maximal between-row distance; Min. with.-row dist. = minimal within-row distance; 1.5 $2 \mathrm{~m}$ with.-row dist $=$ within-row distance between 1.5 and $2 \mathrm{~m}$; Max. with-row dist $=$ maximal within-row distance; Lower dens. $=$ density inferior to 1250 trees $\cdot \mathrm{ha}^{-1} ; 1250-1500$ dens. $=$ density between 1250 and 1500 trees $\cdot \mathrm{ha}^{-1} ; 1500-1800$ dens. = density between 1500 and 1800 trees $\cdot \mathrm{ha}^{-1}$; higher dens. = density greater than 1800 trees $\cdot \mathrm{ha}^{-1}$.

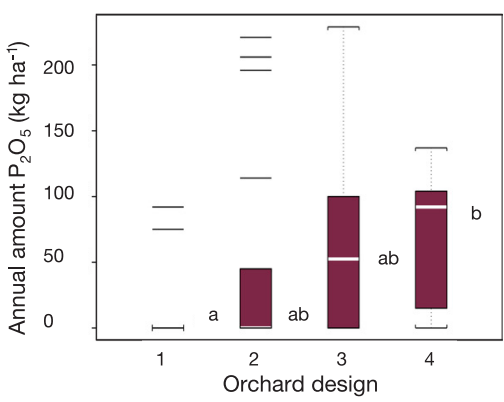

Figure 3. Box plots representing the annual amounts of $\mathrm{P}_{2} \mathrm{O}_{5}$ according to the orchard design. See legend of Figure 2 for the description of the different elements of the plot. The horizontal white layer represents the median. Different letters situated in front of the median indicate significant differences at the $P<0.05$ level with a Noether test.

also consistent with the fact that $21 \%$ of plots of groups 3 or 4 are drip-irrigated against less than $3 \%$ for plots of groups 1 or 2. The vigour of the orchard is possibly another explanation. It is described as "very high" by farmers for $40 \%$ of the plots of group 1 (which is consistent with the high frequency of vigorous rootstocks in this group), $23 \%$ of group 2 and only $1 \%$ of groups 3 and 4 . Thus, we can suppose that vigorous orchards are taller with a higher leaf area index and so a higher evaporative demand.

Another example concerns the annual input of $\mathrm{P}$ according to orchard designs (Fig. 3). Old orchards (group 1) receive significantly less P fertiliser than young orchards (group 4). This can be interpreted considering that the phosphorous fertilisation effect is staggered over a long period, and therefore is an investment for producers. So, old plots, which are intended to soon be uprooted (groups 1 and 2 are mainly composed of Golden which is nowadays the least profitable variety among

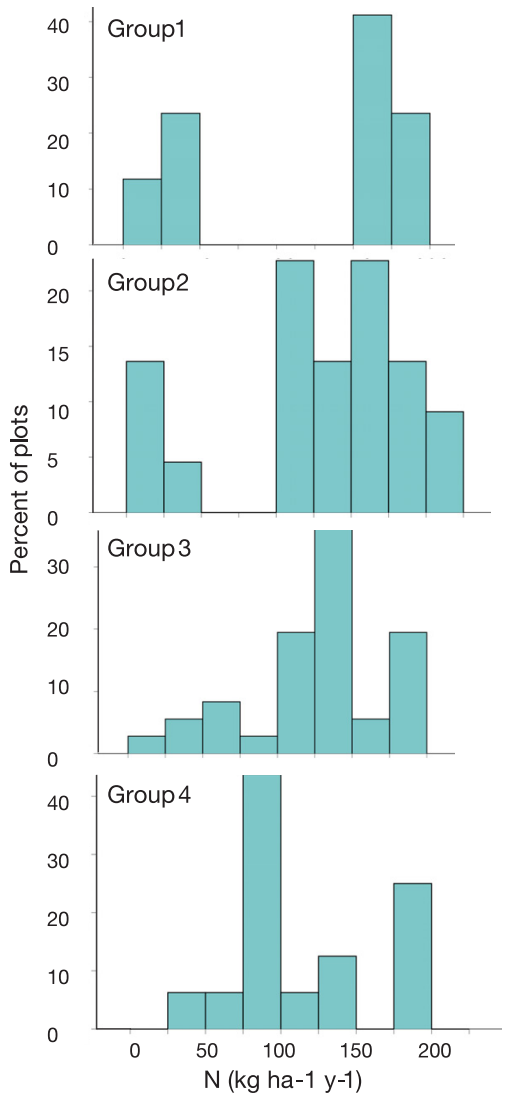

Figure 4. Distribution of nitrogen inputs $\left(\mathrm{kg} \mathrm{N} \cdot \mathrm{ha}^{-1} \cdot \mathrm{y}^{-1}\right)$ according to the orchard design.

the three studied) receive significantly less amendment fertilisation. The same result was obtained with potassium fertilisation (data not shown).

On the contrary, the nitrogen inputs were not significantly discriminated by orchard designs. The distribution of the amounts applied for each group is shown in Figure 4. Although inputs are dispersed for groups 2 and 4, group 3 is rather centred between 100 and $150 \mathrm{~kg} \mathrm{~N} \cdot \mathrm{ha}^{-1} \cdot \mathrm{y}^{-1}$, which is in the range of the prevalent technical recommendation [36]. Group 1 presents a distribution around two poles: small inputs (less than $50 \mathrm{~kg} \mathrm{~N} \cdot \mathrm{ha}^{-1} \cdot \mathrm{y}^{-1}$ ) and high inputs (more than $150 \mathrm{~kg} \mathrm{~N} \cdot \mathrm{ha}^{-1} \cdot \mathrm{y}^{-1}$ ). This fact seems inconsistent with the current knowledge on nitrogen requirements of apple orchards [36]. This distribution can be interpreted considering the orchard vigour (the modality "very high" is mainly represented in group 1) and the action of nitrogen on tree vigour $[19,28,40]$ : the first pole could represent plots in which farmers would like to reduce the vigour by reducing the nitrogen inputs. On the contrary, the second pole could correspond to plots in which farmers want fertilisation to fit the higher crop requirements (due to its high supposed LAI).

\subsubsection{Crop load management}

The number of dormant pruning hours changes according to orchard design (Fig. 5). Group 3 needs significantly less 


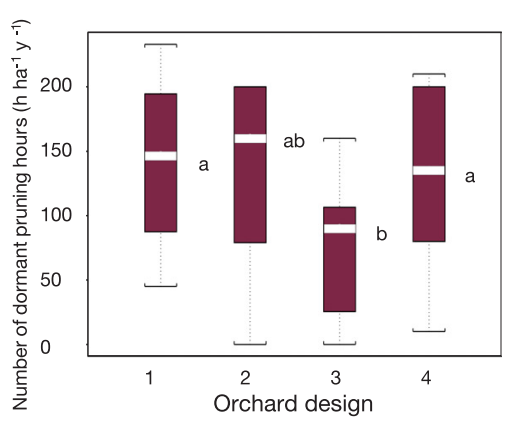

Figure 5. Box plots representing the number of dormant pruning hours according to the orchard design. See legend of Figure 2 for the description of the different elements of the plot. Different letters situated in front of the mean indicate significant differences at the $P=$ 0.05 level with a Tukey test.

dormant pruning than other groups. It is mainly composed of the Granny cultivar (53\% of plots, Tab. II) whose pruning requirements are low (Tab. I). Also, the Solaxe tree shape is significantly represented in this 3rd group, and this shape was namely elaborated to reduce the required pruning efforts [22]. Explanations can also be given for high pruning hours in groups 1 and 2 . These orchards may certainly need restructuring to cut old branches, to reduce the tree height, and to shift from an old tree shape to a new one $(69 \%$ of the plots of group 1 used to be conducted as hedgerow systems and are now restructured). Moreover, old orchards are often scionrooting, which usually increases the vigour of the trees and subsequently the pruning requirements.

Manual thinning is also discriminated by orchard design (although differences are not significant at the $P<5 \%$ level, data not shown). Plots of group 4 are manually thinned much more than other plots: they receive 50 hours per year on average, while plots of groups 1 to 3 receive around 15 hours per year on average. Group 4 is mainly composed of the Gala cultivar and its clones. This variety is a bicolour one and therefore needs a significant amount of sunlight; manual thinning helps to choose the fruits that are the best exposed to light. Although manual thinning is considered as necessary on all varieties to increase fruit quality [8], its cost is often prohibitive for farmers, except on Gala plots, that were indeed the most economically profitable in 1998-1999.

The number of fruit branches per tree is an important indicator for dormant pruning [23, 24]. We thus considered its knowledge by the farmer as an indicator of technical level for his pruning management. The number of fruiting branches per tree is known by farmers for $40 \%$ of the plots in groups 3 or 4 against $10 \%$ of the plots in groups 1 or 2 . This suggests a link between the technical level of crop load management and the age of the plot. The same result is obtained for the flowering rate, that is useful to help thinning management (data not shown). A possible explanation is given in Figure 6, which shows that the plots of group 1 are mainly cultivated by old farmers whereas the plots of groups 3 and 4 mainly belong to younger farmers who may have more technical and recent knowledge than older ones.

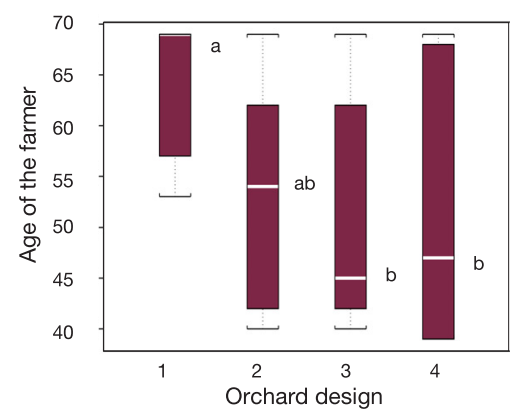

Figure 6. Box plots representing the age of farmers according to the orchard design. See legend of Figure 2 for the description of the different elements of the plot. The horizontal white layer represents the median. Different letters situated in front of the median indicate significant differences at the $P<0.05$ level with a Noether test.

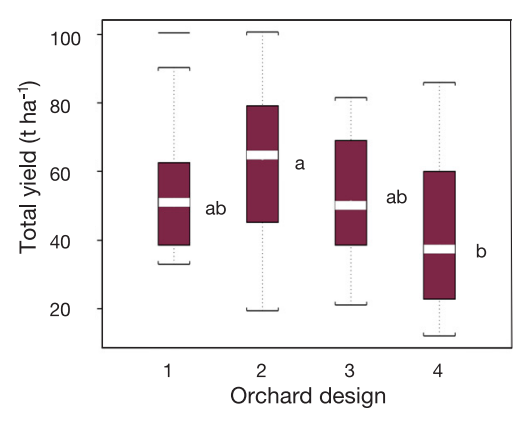

Figure 7. Box plots representing the total yield according to the orchard design. See legend of Figure 2 for the description of the different elements of the plot. The horizontal white layer represents the median. Different letters situated in front of the median indicate significant differences at the $P<0.05$ level with a Noether test.

\subsection{How do orchard designs influence agronomical performances?}

Figure 7 shows that the total fresh yield is influenced by the orchard design and that group 2 is the most productive, whereas group 4 has the lowest yield. Granny and Smothee, well represented in group 2, are recognised to be highly productive. However, the yield per tree is not the best in group 2 (the best performance is in group 1 with around $60 \mathrm{~kg} \cdot$ tree $^{-1}$ against $35 \mathrm{~kg}$ for the 3 other groups). Group 2 has the highest yield $\cdot \mathrm{ha}^{-1}$ due to its highest tree density. An explanation for the lowest performance of group 4 can be given if we consider that Gala, which is the main cultivar represented in this group, was the most economically profitable variety and that high yield can be antagonistic to high fruit quality [9]. Therefore, farmers may have tried to reduce the fruit load for this variety [41].

The firmness rating is also different according to the orchard design, as shown in Figure 8. Apples in groups 3 and 4 seem to be significantly firmer than in group 1. Firstly, Granny and Gala, which are well represented in the last two groups, are generally firmer than Golden (Tab. I). Secondly, 


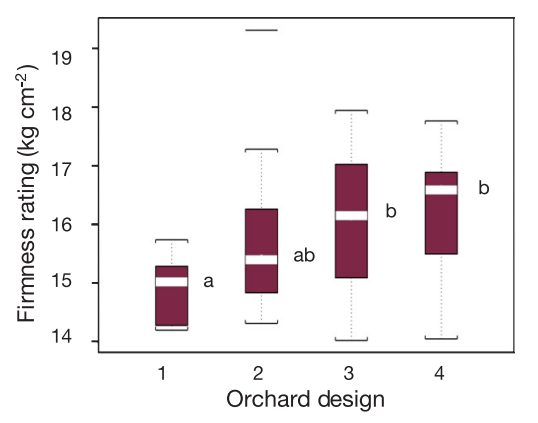

Figure 8. Box plots representing the firmness rating according to the orchard design. See legend of Figure 2 for the description of the different elements of the plot. Different letters situated in front of the mean indicate significant differences at the $P=0.05$ level with a Tukey test.

groups 1 and 2 receive more water than other groups (Fig. 2) and high irrigation water amounts are recognised to be antagonistic to a high firmness rating. In addition, no link was encountered between orchard design and sugar content (data not shown).

The distribution of visual defaults (Tab. III) is largely determined by 5 main defaults (among 21 possibilities) and the "non-defective" character. Classes of visual fruit defaults are influenced by orchard designs (Tab. IV). Fruits of plots belonging to class 1 are mainly marked by hail. For class 2 , the majority of fruits does not present any default. Class 3 is intermediate between classes 2 and 4 . Class 4 cumulates a maximum of defaults such as knock during harvesting and effects of codling moth bites and scab. A cross-tabulation relating this default classification to the orchard designs (Tab. IV) shows that old orchards (groups 1 and 2) correspond mainly to classes 3 and 4 of fruit defaults. On the contrary, younger orchards (groups 3 and 4) correspond to class 2, in which fruits present less defaults. No biological susceptibility of the varieties to visual defaults can explain such a distribution. On the contrary, Golden being the less profitable variety, we can suppose that farmers pay less attention to Golden plots, i.e. plots of groups 1 and 2. Other interpretations could be that the vigour of the older plots, which is described as very high, may induce a microclimate that is more favourable to the development of

Table III. Main visual fruit defaults, classified according to the medoid clustering method. Data are given, for each class, as a percentage. For instance, for plots belonging to class 1, an average of $8.2 \%$ of the fruits present knock marks. Bold numbers indicate, on one row, the most discriminant values contributing to the formation of the classes.

\begin{tabular}{lcccc}
\hline Mean (\%) & Class 1 & Class 2 & Class 3 & Class 4 \\
\hline Knock & 8.2 & 8.0 & $\mathbf{1 5 . 8}$ & $\mathbf{2 7 . 1}$ \\
Russeting & 12.6 & $\mathbf{6 . 2}$ & 13.5 & 20.1 \\
Codling moth bite & 1.2 & 0.6 & 0.6 & $\mathbf{4 . 3}$ \\
Scab & 0.1 & 0.6 & $\mathbf{2 . 0}$ & $\mathbf{9 . 3}$ \\
Hail mark & $\mathbf{2 9 . 5}$ & 5.0 & 3.5 & 4.8 \\
No default & 37.7 & $\mathbf{6 4 . 1}$ & 47.3 & 21.8 \\
\hline
\end{tabular}

Table IV. Cross-tabulation between orchard designs (rows) and visual fruit defaults (columns). The number of plots at each intersection is given and the number between brackets represents the relative frequency for one row. The chi-squared test cannot be performed due to too small numbers.

\begin{tabular}{cccccc}
\hline & & \multicolumn{4}{c}{ Visual fruit defaults } \\
\cline { 3 - 6 } & & Class 1 & \multicolumn{1}{c}{ Class 2 } & Class 3 & Class 4 \\
\hline & Group 1 & 0 & 2 & 4 & 6 \\
& & $(0)$ & $(0.17)$ & $(0.33)$ & $(0.50)$ \\
Orchard & Group 2 & 3 & 5 & 7 & 0 \\
designs & Group 3 & $(0.20)$ & $(0.33)$ & $(0.47)$ & $(0)$ \\
& & $(0.25)$ & $(0.46)$ & $(0.25)$ & $(0.04)$ \\
& Group 4 & 0 & 6 & 2 & 1 \\
& & $(0)$ & $(0.67)$ & $(0.22)$ & $(0.11)$ \\
\hline
\end{tabular}

apple scab [32] or would reduce the effectiveness of chemical spraying.

\section{DISCUSSION}

\subsection{Limits and interests of the study}

One can consider that only 91 plots may restrict the possibility of extrapolating our results. However, if we consider that the target population is the co-operative, the extrapolation capacity is maintained since the statistical sample tends to cover all the co-operative plots. Moreover, the sample presented here summarises a large part of the variability which can be encountered in French apple orchards [7]. The planting dates range from the early 1960's to 1995 . Thus, all "designs" are encountered: from extensive to modern orchards, passing by intensive orchards of the 1970s, with the three main varieties cultivated in France. Moreover, the soils on which these orchards are planted correspond typically to the location of apple tree production. Therefore, this sample is likely to represent the Southern French apple orchards, enlarging the validity domain of our results.

Another limitation of this study is due to the fact that only one year was considered. This year was quite "normal" from a climatic point of view, but an inter-annual variability can exist for agronomical performances (submitted to the influence of the climate but also of the alternate fruit bearing) and for cultural practices (fertilisation, irrigation and, to a lesser extent, pruning). However, as the sample is made up of orchards with various ages and histories, we consider that all plots do not react in the same way to the same external factor. Therefore, we assume, as a first approximation, that the variability due to orchard designs is higher than that which could be introduced by an "annual effect". A repetition of this study over a few subsequent years would be necessary to test this hypothesis. Nevertheless, this one-year sample was enough to demonstrate the perennial effect of orchard designs.

A major criticism could be addressed about the non-consideration of crop protection practices in our work. As previously mentioned, we first supposed that crop protection practices were at the agronomical maximum. To test this hypothesis, we 
classified plots described by the visual fruit defaults. This classification showed that plots of the 3rd and 4th default classes do not benefit from a maximum crop protection. In addition, plots poorly conducted for apple scab protection are also badly protected against codling moth. So, we are forced to reject our hypothesis and this reinforces the need to link analysis of crop protection and other agronomical practices, which are often led independently $[16,38]$. We also consider that the methodology hereby proposed opens an easy way to study the performances of crop protection practices and could be applied in PO.

\subsection{Signification of orchard designs: planting and tree management fashion}

The orchard design typology discriminates both cultural practices and agronomical performances. This typology gathers or corresponds to several effects: variety, farmer and economical effects, which may influence long-term orchard management and crop care.

Orchard designs can be read in various ways. First, they represent different planting "fashions" and intensification levels. Group 1 gathers older low intensive Golden orchards (low density, vigorous rootstock and intermediate productive variety). On the contrary, group 2 represents highly intensive orchards (very high density, dwarfing rootstock and Granny, a highly productive variety). Groups 3 and 4 represent younger orchards with moderate technical choices (moderate density, dwarfing rootstock and a moderately productive variety, i.e. Gala) with "modern options" (drip irrigation and Solaxe shape). This temporal evolution of orchard designs has also been mentioned by Chazoule and Desplobins [7] in their historical and sociological study. They distinguished three periods, from post-war to the early 1960s, from 1960 to the early 1980s and from the early 1990s to now. These authors also noticed that these changes were accompanied by an evolution from empirical toward formalised knowledge, a strengthening of the place of partners (researchers, technicians and nursery gardeners) and an evolution in marketing, with a strong need to produce high quality fruits.

This typology can also be read considering the evolution of tree management shown by Lauri and Lespinasse [21] and Lespinasse [27]. They demonstrated that the evolution of knowledge concerning reproductive and vegetative growth balance is consistent with the evolution of fruit growing (tree shape, orchard density and type of pruning). For instance, they showed that renewal pruning, on which the hedgerow shape is based, was increasing the vegetative growth (and so, the need for pruning) and the alternate fruit bearing and was favouring fruits located inside the tree, a position incompatible with bicolour varieties. This may explain why the hedgerow system has been abandoned or is only practised in older orchards (group 1). Another example can be found in group 4 where techniques leading to the maximisation of light interception in order to increase coloration of bicolour varieties (i.e., Gala) have been adopted.

Thus, we can argue that the sample studied here reflects the evolution in plant knowledge and technical advice for orchard management in Southern France. It is also interesting to notice that farmers' planting practices are close to those recom- mended by both agronomical research and extension workers. To our knowledge, this concordance has rarely been studied on the basis of observed practices but is generally described only through expert knowledge.

\subsection{Comparison between orchard design and other orchard concepts}

The concept of orchard design enables the summarisation of information based on numerous variables: variety, rootstock, distances of planting, tree shape and time of planting. It differs from the orchard system, which is sometimes used [2, 31]. The latter concerns the same variables as orchard design, but from a synchronic point of view, without consideration of the history and cumulated effects of past cultural operations. Another difference between the orchard system and orchard design is that the first one is given a priori and results from theoretical considerations, and the second one results from actual observations on commercial orchards. Therefore, it appears a posteriori and is a way of organising the orchard cropping system diversity.

Another concept used in viticulture is the training system, expressed as a "set of techniques (geometry of planting, shaping and regular pruning, vegetation management) which define the vine stock shape and its vegetation" [6]. This concept is more integrative than ours. It does not allow the separation of the cultural operations performed at planting (planting scheme and shaping pruning) from those realised during the adult phase of the vineyard (regular pruning and vegetation management).

\subsection{Orchard design and research on perennial crops}

Perennial crops have a "memory" of past cultural practices and therefore the present orchard functioning depends on what happened to the crop in the previous years. Consequently, the comparison between present orchards cannot be realised without considering their history, taking into account long-term determinants of perennial cropping systems. As a result, to apply regional agronomical diagnosis [12] to fruit production, a method identifying cultural practices leading to low agronomical results, the samples used should be nested according to their orchard design.

Our results suggest a strong coherence between orchard descriptors and cultural operations. For instance, vigour seems to be a central variable as it may influence the fertilisation, the irrigation or the dormant pruning and is related to the planting choices. The variety is also a central variable as it partly determines tree shape (but not always: it is possible to encounter Gala plots conducted as Golden orchards) or crop performances. Such consistency is a typical aspect of cropping systems analysis [30] and has already been mentioned in apple production [3].

If the orchard design appears a convenient way to define a potential (of yield, of vigour, etc.) of the plot, the observed cropping system and crop performances are the result of the interaction between this potential, the present pedoclimatic context and the farmer's management. The crop management sequence is therefore a way of orienting the orchard towards 
its potential or in another direction (see Fig. 4 and Sect. 3.2.1). This is to be related to the low capacity of the orchard design to explain agronomical performances, and reinforces the need for research based on plant modelling that would consider the inputs of cultural operations and pedoclimatic conditions to predict the orchard performance [25].

\section{CONCLUSION}

Orchard design allows a comprehensive approach of several variables concerning planting choices observed in farmer plots. The typology derived from this notion discriminates four groups that correspond to different planting periods. It discriminates present cultural practices and even some agronomical performances. A set of practice determinants is hypothesised when confronting cultural practices with the classes of the typology. This gives a better understanding of the plant-environment-technique system [14]. The orchard design concept can be considered as the result of planting choices and past crop management sequences. It may be an important element to take into account in regional agronomical diagnosis.

However, this study raises several questions about the combination of different orchard designs in one farm and we can wonder whether such a dispersion is a goal or a disadvantage for farmers. Orchard design combination in a co-operative, as it seems to lead to agronomical performance variability, may also be a problem [5] in terms of fruit allotment or stock management. Different strategies are therefore possible for the PO: reducing the variability, or segmenting the harvest into homogeneous or origin-dependent lots. An original study could be led on that topic, considering the orchard design as a way of discriminating the plots.

Acknowledgements: We sincerely thank Georges Fandos for his help with data collection and the farmers who answered the survey. This work was funded by the INRA national programme on Integrated Fruit Production "Action Transversale 67, Production Fruitière Intégrée".

\section{REFERENCES}

[1] Baize D., Girard M.-C., Référentiel pédologique, INRA, Paris, 1995.

[2] Barritt B.H., Orchard sytems research with deciduous trees: a brief introduction, HortScience 22 (1987) 548-549.

[3] Bellon S., Lescourret F., Calmet J.P., Characterisation of apple orchard management systems in a French Mediterranean Vulnerable Zone, Agronomie 21 (2001) 200-213.

[4] Boiffin J., Sebillotte M., Influence des conditions écologiques et de l'histoire culturale sur le rendement du maïs grain. Analyse de 8 campagnes sur un essai de longue durée, Ann. Agron. 26 (1975) 555-591.

[5] Caneill J., Le Bail M., Contribution de l'agronome à la gestion d'un bassin d'approvisionnement, in: Nicolas F., Valceschini E. (Eds.), Agroalimentaire, une économie de la qualité, INRA Editions/Economica, Paris, 1995, pp. 391-399.

[6] Carbonneau A., Influence de la conduite du vignoble sur la qualité des vins, C.R. Acad. Agric. Fr. 76 (1990) 13-21.
[7] Chazoule C., Desplobins G., Codification des techniques et relance des variétés : le cas Cripps Pink cov - Pink Lady, in: Bye P. (Ed.), Domestiquer le végétal, INRA, ESR, 1999, pp. 133-154.

[8] Darbellay C., Aerny J., Dessimoz A., Evequoz N., Maîtrise de la récolte et de la qualité des fruits en culture de Pommiers Maigold. $2^{\mathrm{e}}$ partie : influence de la charge sur la qualité des fruits, Rev. Suisse Vitic. Arboric. Hortic. 27 (1995) 151-156.

[9] Daugaard H., Grauslund J., Fruit colour and correlations with orchard factors and post-harvest characteristics in apple cv. Mutsu, J. Hortic. Sci. Biotech. 74 (1999) 283-287.

[10] Debaeke P., Effets à moyen et à long terme des systèmes de culture sur la flore adventice : intérêt de la modélisation pour cette approche, in: Combe L., Picard D. (Eds.), Un point sur les systèmes de culture, INRA, Versailles, 1990, pp. 57-68.

[11] Debaeke P., Sebillotte M., Modélisation de l'évolution à long terme de la flore adventice. I. Construction d'un modèle descriptif de l'évolution quantitative du stock de semences de l'horizon travaillé, Agronomie 8 (1988) 193-403.

[12] Doré T., Sebillotte M., Meynard J.M., A diagnostic method for assessing regional variation in crop yield, Agric. Syst. 54 (1997) 169-188.

[13] Escofier B., Pagès J., Analyses factorielles simples et multiples, Bordas, Paris, 1988.

[14] Gras R., Benoit M., Deffontaines J.P., Duru M., Lafarge M., Langlet A., Osty P.L., Le fait technique en agronomie : activité agricole, concepts et méthodes d'étude, L'Harmattan, Paris, 1989.

[15] Habib R., Bellon S., Codron J.M., Gendrier J.P., Lescourret F., Lauri P.-E., Lespinasse Y., Navarette M., Plenet D., Pluvinage J., de Sainte-Marie C., Sauphanor B., Simon S., Toubon J.-F., Développement de la Production Fruitière Intégrée : de nouveaux enjeux pour la recherche agronomique, European Farming and Rural Systems Research and Extension into the next Millenium. Environmental, agricultural and socio-economic issues, Volos, Greece, 2000 .

[16] Habib R., Lescourret F., Highlights on integrated production systems: current research and proposal for the future, Acta Hortic. 495 (1999) 307-312.

[17] Habib R., Nesme T., Plénet D., Lescourret F., Data modelling for database design in apple production monitoring systems for a producer organization, Acta Hortic. 566 (2001) 477-482.

[18] Hernanz J.L., Lopez R., Navarrete L., Sanchez-Giron V., Longterm effect of tillage systems and rotations on soil structural stability and organic carbon stratification in semiarid central Spain, Soil Till. Res. 66 (2002) 129-141.

[19] Huett D.O., Prospects for manipulating the vegetative-reproductive balance in horticultural crops through nitrogen nutrition: a review, Aust. J. Agric. Res. 47 (1996) 47-66.

[20] Latif M.A., Mehuys G.R., Mackenzie A.F., Alli I., Faris M.A., Effects of legumes on soil physical quality in a maize crop, Plant and Soil 140 (1992) 15-23.

[21] Lauri P.E., Lespinasse J.M., Apple tree training in France: current concepts and practical implications, Fruits 54 (1999) 441-449.

[22] Lauri P.E., Lespinasse J.M., De l'axe vertical au solaxe, vers un renouvellement des concepts, Fruit Belg. 477 (1999) 25-31.

[23] Lauri P.E., Lespinasse J.M., Intérêt agronomique de la branche fruitière du pommier pour une production régulière et de qualité, Rev. Suisse Vitic. Arboric. Hortic. 31 (1999) 161-166.

[24] Lauri P.E., Terouanne E., Lespinasse J.M., Relationship between the early development of apple fruiting branches and the regularity of bearing. An approach to the strategies of various cultivars, J. Hortic. Sci. Biotech. 72 (1997) 519-530.

[25] Lescourret F., Habib R., Génard M., Agostini D., Chadoeuf J., Pollination and fruit growth models for studying the management of kiwifruit orchards. 1. Models description, Agric. Syst. 56 (1998) 67-89. 
[26] Lespinasse J.M., La conduite du pommier. Type de fructification, incidence sur la conduite de l'arbre, INRA, Paris, 1977.

[27] Lespinasse J.M., Apple orchard management practices in France, from the vertical axis to the solaxe, Compact Fruit Tree 29 (1996) 83-88.

[28] Lobit P., Soing P., Génard M., Habib R., Effects of timing of nitrogen fertilization on shoot development in peach (Prunus persica) trees, Tree Physiol. 20 (2001) 35-42.

[29] MathSoft, S-Plus 2000. Guide to statistics, MathSoft, Seattle, 1999.

[30] Meynard J.M., Doré T., Habib R., L'évaluation et la conception de systèmes de culture pour une agriculture durable, C.R. Acad. Agric. Fr. 87 (2001) 223-236.

[31] Monney P., Charles B., Modes de conduite en arboriculture fruitière. 1 - Réflexions sur les performances des nouveaux systèmes de verger, Rev. Suisse Vitic. Arboric. Hortic. 25 (1993) 87-97.

[32] Penrose L.J., Nicol H.I., Aspects of microclimate variation within apple tree canopies and between sites in relation to potential Ven turia inaequalis infection, N.Z. J. Crop Hortic. 24 (1996) 259-266.

[33] Sansavini S., Integrated fruit production in Europe: research and strategies for a sustainable industry, Sci. Hortic. 68 (1997) 25-36.

[34] Scherrer B., Biostatistique, Gaëtan Morin, Chicoutimi, Québec, Canada, 1984
[35] Sebillotte M., Systèmes de culture, un concept opératoire pour les agronomes, in: Combe L., Picard D. (Eds.), Un point sur les systèmes de culture, INRA éditions, Versailles, 1990, pp. 165-196.

[36] Soing P., Fertilisation des vergers, environnement et qualité, CTIFL, Paris, 1999

[37] Sprent P., Ley J.P., Pratique des statistiques non paramétriques, INRA, Paris, 1992.

[38] Toubon J.F., Les freins à l'adoption des méthodes de protection intégrée dans les vergers de la région d'Avignon, $5^{\mathrm{e}}$ conférence internationale sur les ravageurs en agriculture, Montpellier, France, 1999.

[39] Trillot M., Masseron A., Tronel C., Pomme, les variétés, CTIFL, Paris, 1993.

[40] Weinbaum S.A., Johnson R.S., DeJong T.M., Causes and consequences of overfertilization in orchards, HortTechnology 2 (1992) $112-121$.

[41] Wojcik P., Rutkowski K., Treder W., Quality and storability of "Gala" apples as affected by crop load, Folia Hortic. 13 (2001) 8996.

[42] http://www.brmfl.com/pages/fr/fiche_produit_fr.cfm?id=2 (verified on $05 / 27 / 2003$ ) 